Vol. 23, No. 2, September 2020, hlm. 165-179

p-ISSN: 1410-9344; e-ISSN: 2549-5631

homepage: http://journals.ums.ac.id/index.php/warta

\title{
Penguatan Literasi Mitigasi Bencana Angin Puting Beliung untuk Peningkatan Kapasitas Masyarakat Desa Munggur, Kabupaten Boyolali, Jawa Tengah
}

\author{
${ }^{1}$ Yunus Aris Wibowo, ${ }^{1}$ Ratih Puspita Dewi, ${ }^{2}$ Lintang Ronggowulan, ${ }^{1}$ Rhizki Yulia Anjarsari, \\ ${ }^{1}$ Yunita Miftakhunisa \\ ${ }^{1}$ Program Studi Pendidikan Geografi, Fakultas Keguruan dan Ilmu Pendidikan, Universitas Muhammadiyah \\ Surakarta \\ ${ }^{2}$ Program Studi Pendidikan Geografi, Fakultas Keguruan dan Ilmu Pendidikan, Universitas Sebelas Maret, \\ Surakarta \\ Email: 1yunus.a.wibowo@ums.ac.id
}

\section{Article Info}

Submitted: 20 March 2019

Revised: 13 April 2020

Accepted: 17 April 2020

Published: 5 May 2020

Keywords : capacity, local wisdom, local knowledge tornado, disaster risk reduction
Kata Kunci : kapasitas, kearifan lokal, pengetahuan lokal, pengurangan risiko bencana, puting beliung

\section{Abstract}

Boyolali Regency is one of the most suffer area to tornado (puting beliung in Bahasa Indonesia). It annually occured before the rainy season arrives and has resulted in material losses and injurie. One of the villages in Boyolali which is often hit by a tornado is Village of Munggur. Therefore, the purpose of this activity is increasing to the capacity of community of Munggur Village, Boyolali Regency by strengthening to literacy of tornado mitigation. The effort was carried out through education by conducting focus group discussion (FGD). The FGD was attended by 50 residents, head of Munggur Village, village officials and community leaders. The FGD begins with the presentation of material that contains scientific knowledge, followed by a question and answer session. The result of education through FGD was an improvement in the literacy of the Munggur Village community about the tornado disaster and its mitigation which is integrated with the local knowledge and local wisdom, so that synergy occurs between local knowledge, local wisdom and scientific knowledge. The synergy is expected to improve the capacity of the community, so that the level of disaster risk can be reduced.

\footnotetext{
Abstrak

Kabupaten Boyolali merupakan salah satu wilayah yang sering terdampak bencana angin puting beliung. Bencana angin puting beliung hampir setiap tahun terjadi menjelang musim hujan tiba dan mengakibatkan kerugian material serta korban luka. Salah wilayah di Kabupaten Boyolali yang sering terdampak bencana angin puting beliung adalahi Desa Munggur. Oleh karena itu, kegiatan ini bertujuan sebagai Penguatan Literasi Mitigasi Bencana Angin Puting Beliung
} 
untuk Peningkatan Kapasitas Masyarakat Desa Munggur, Kabupaten Boyolali, Jawa Tengah. Upaya tersebut dilakukan melalui edukasi yang dilakukan dalam focus group discussion (FGD). FGD tersebut dihadiri oleh 50 warga, kepala desa, perangkat desa serta tokoh masyarakat. FGD dimulai dengan pemaparan materi yang berisi pengetahuan ilmiah (scientific knowledge), dilanjutkan dengan sesi tanya jawab. Hasil edukasi adalah peningkatan literasi masyarakat Desa Munggur tentang bencana angin puting beliung serta upaya mitigasinya yang diintegrasikan dengan kearifan lokal (local knowledge), sehingga terjadi sinergi antara kearifan lokal (local knowledge) dan pengetahuan ilmiah (scientific knowledge). Sinergi tersebut diharapkan dapat meningkatkan kapasitas (capacity) masyarakat, sehingga tingkat risiko (risk) bencana angin puting beliung dapat diturunkan.

\section{PENDAHULUAN}

Bencana merupakan serangkaian peristiwa baik yang terjadi secara alami maupun karena akibat dari aktivitas manusia yang menimbulkan kerugian korban jiwa, material maupun sosial (Dube, 2020; Marshall, 2020; Wamsler \& Johannessen, 2020). Bencana merupakan konsekuensi negatif dari bahaya (hazard) dan kerentanan (vulnerability). Kejadian bencana dan kerugian akibat bencana meningkat secara drastis dalam beberapa dekade terakhir (Wang et al., 2019)the occurrence and severity of disasters has greatly increased over recent decades. The importance of community-based disaster risk reduction (CBDRR. Oleh karena itu, dapat disimpulkan bahwa suatu peristiwa dapat dikategorikan sebagai bencana, jika peristiwa tersebut menimbulkan kerugian bagi manusia (Gaillard et al., 2019). Tingkat kerugian akibat bencana bergantung kepada jenis kejadian, frekuensi, magnitud dan komponen risiko yang terpapar.

Badan Nasional Penanggulangan Bencana Nasional (BNPB), mengklasifikasikan bencana ke dalam 13 jenis, yaitu gempabumi, Tsunami, banjir, tanahlongsor, letusan gunungapi, gelombang ekstrim dan abrasi, cuaca ekstrim, kekeringan, kebakaran hutan dan lahan, kebakaran gedung dan pemukiman, epidemi dan wabah penyakit, gagal teknologi dan konflik sosial (BNPB, 2012). Hal itu diperkuat oleh United Nations Office for Disaster Risk Reduction (UNISDR, 2009) yang mengklasifikasikan fenomena yang berpotensi mengakibatkan bencana menjadi tiga jenis, yaitu hidrometeorologis (hydrometeorological), geologis (geological) dan biologis (biological). Kedua klasifikasi tersebut menggambarkan betapa banyaknya kejadian yang berpotensi menjadi bencana.

Potensi ancaman/bahaya yang begitu banyak, khususnya di Indonesia merupakan tantangan baik bagi pemerintah maupun masyarakat. Oleh karena itu, diperlukan manajemen bencana yang baik. Peran aktif pemerintah dalam manajemen bencana ditunjukkan dengan membentuk BNPB dan BPBD hingga tingkat kota/kabupaten. Selain peran aktif pemerintah, hal yang sangat penting dalam manajemen bencana adalah kerjasama masyarakat di Kawasan rawan bencana. Kawasan Rawan Bencana (KRB) merupakan wilayah yang ditentukan berdasarkan tingkat kemudahan wilayahnya untuk terpapar atau terdampak suatu bencana. KRB juga ditentukan berdasarkan jenis bencana. Salah satu wilayah yang berpotensi terdampak beberapa jenis bencana adalah Kabupaten Boyolali, Provinsi Jawa Tengah.

Salah satu kejadian bencana yang paling sering melanda Kabupaten Boyolali adalah bencana angin puting beliung. Puting beliung jika ditinjau berdasarkan klasifikasi menurut BNPB, maka termasuk dalam fenomena cuaca ekstrim, sedangkan berdasarkan klasifikasi UNISDR termasuk ke dalam fenomena hidrometeorologis. Puting beliung merupakan angin ribut yang identik dengan pusaran berbentuk seperti corong yang bergerak dengan kecepatan tinggi dan memiliki daya rusak tinggi bagi wilayah yang dilaluinya (Refan et al., 2020). 
Puting beliung kebanyakan terjadi pada wilayah beriklim tropis. Kabupaten Boyolali terletak di Jawa Tengah yang beriklim tropis dengan kelembaban udara di atas $75 \%$ dan suhu udara yang relatif tinggi karena pengaruh posisi dan penyinaran matahari. Hal itu menyebabkan wilayah Kabupaten Boyolali rawan terhadap angin puting beliung selain karena pengaruh pergerakan angin muson (monsun) barat dan timur.

Angin puting beliung sebenarnya bersifat lokal ditinjau dari lokasi kejadian dan dampak yang ditimbulkan. Namun demikian, kejadian tersebut telah menimbulkan banyak kerugian baik secara material maupun non material (Diaz \& Joseph, 2019; Lim et al., 2017). Kejadian bencana puting beliung merupakan kejadian yang paling sering melanda Kabupaten Boyolali dalam rentang Tahun 1980-2020 (Gambar 1).

Gambar 1 menunjukkan banyaknya kejadian bencana puting beliung yang melanda Kabupaten Boyolali dalam kurun waktu 30 tahun terakhir. Kejadian bencana khususnya bencana alam akan sulit atau bahkan mustahil untuk dihilangkan. Dalam konteks penanggulangan bencana, baik bencana alam maupun non alam memiliki unsur ketidakpastian (uncertainty), sehingga hal yang paling mungkin dilakukan adalah mengurangi potensi kerugian jika bencana melanda (Der Sarkissian et al., 2019; Diaz \& Joseph, 2019;
Wibowo et al., 2019). Upaya tersebut dapat dilakukan dengan meningkatkan kapasitas baik secara struktural maupun non struktural dan melindungi kelompok rentan tidak hanya pada saat bencana melanda tetapi juga pemulihan pasca bencana (Pertiwi et al., 2020; Undangundang Republik Indonesia Nomor 24 Tahun 2007 tentang Penanggulangan Bencana, 2007). Salah satu upaya yang harus secara menyeluruh dilakukan adalah peningkatan kapasitas masyarakat melalui peningkatan pengetahuan tentang mitigasi bencana (Iizuka, 2020; Mutasa \& Munsaka, 2019; Proulx \& Aboud, 2019).

Desa Munggur, Kecamatan Andong merupakan salah satu desa di Kabupaten Boyolali yang sering dilanda bencana puting beliung ditinjau dari kondisi lingkungan serta pengetahuan masyarakatnya (Gambar 2). Kondisi topografi, vegetasi dan penggunaan lahan Desa Munggur yang relatif bervariasi berpotensi memicu peningkatan suhu yang dapat menyebabkan tumbuhnya angin puting beliung. Peningkatan jumlah penduduk dan kepadatan permukiman mengakibatkan menjadi lebih berisiko terdampak bencana (Strader et al., 2018)residential built-environment data for the Central Plains (regional. Oleh karena itu, peningkatan kapasitas masyarakat Desa Munggur perlu dilakukan untuk mengantisipasi apabila kejadian terburuk melanda.

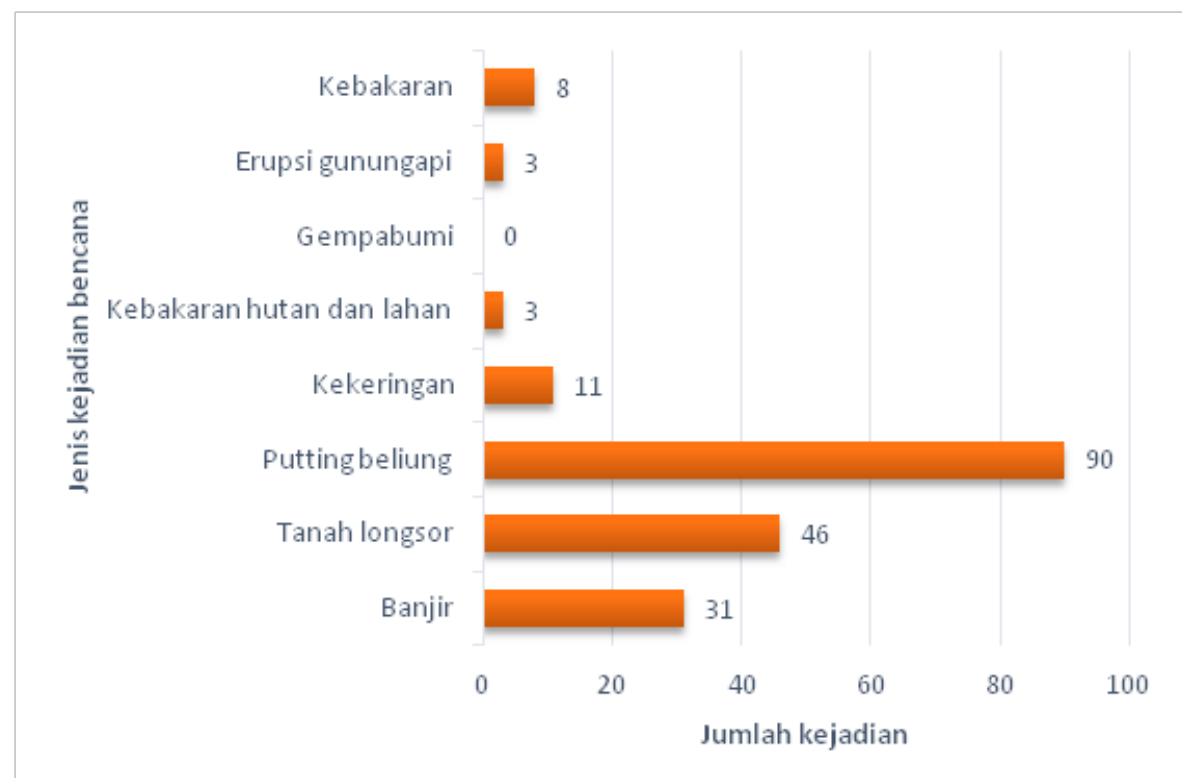

Gambar 1. Kejadian bencana puting beliung di Kabupaten Boyolali dari Tahun 1980-2020 (BNPB, 2017) 


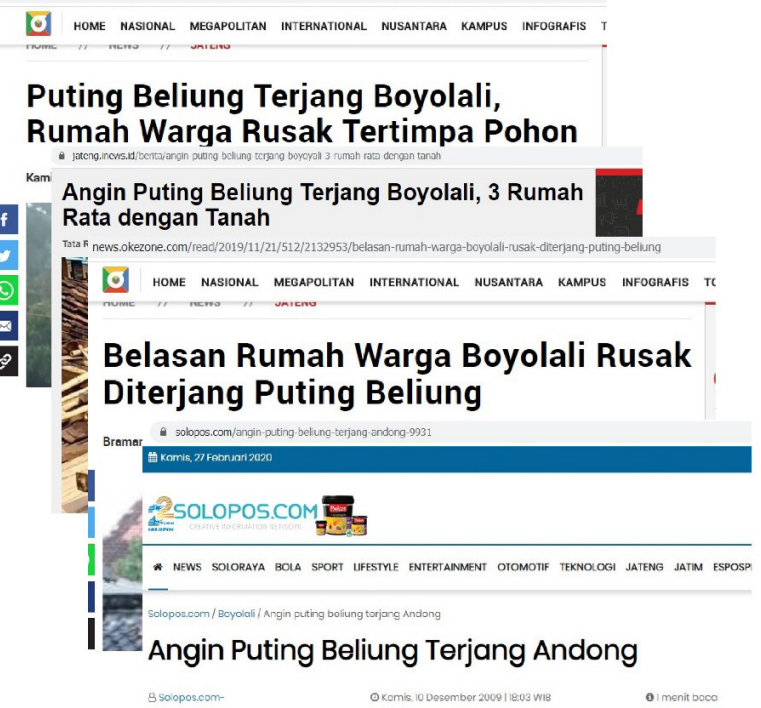

Gambar 2. Kejadian bencana puting beliung di sebagian wilayah Kabupaten Boyolali (jateng. inews.id, 2019; news. okezone.com, 2019; news. okezone.com, 2019; www.solopos.com, 2009)

Hasil peninjauan awal (overview) menunjukkan bahwa masyarakat Desa Munggur sudah memiliki modal yang cukup baik tentang bencana angin puting beliung, yaitu pengetahuan lokal (local knowledge) tentang angin puting beliung dan sudah berkembang menjadi kearifan lokal (local wisdom). Akan tetapi pengetahuan tersebut masih sangat terbatas pada penamaan dan identifikasi waktu kejadian. Lebih lanjut, upaya tanggap darurat yang dilakukan secara turun temurun belum sesuai dengan standar yang diterapkan dalam tanggap darurat bencana. Oleh karena itu, peningkatan pemahaman dan pengetahuan masyarakat tentang puting beliung baik waktu kejadian, ciri-ciri terbentuknya, adaptasi serta mitigasi bencana perlu ditingkatkan (Stokoe, 2016). Meningkatnya pemahaman dan pengetahuan masyarakat Desa Munggur tentang puting beliung diharapkan dapat membangun masyarakat tangguh bencana, sehingga tingkat risiko bencana dapat dikurangi (Amaratunga et al., 2018; Wibowo et al., 2019)in particular when the world is steadily becoming more urbananised. Fast growing cities and urban areas of the world increase disaster risk due to economic growth and fast population expansion. With local governments increasingly taking an important role in the sustainable development, the need for globally comparable knowledge of disasters risks has even become greater. Sound practices that have been tested and implemented by different cities around the world aid knowledge sharing opportunities for future disaster risk reduction. Accordingly, this paper focuses on reported sound practices of local DRR and aims to provide a collection of sound practices on DRR actions at the local level and what needs to be done to reduce future disaster risks. Paper uses the ten essentials identified by the United Nations International Strategy for Disaster Reduction (UNISDR.

Upaya peningkatan literasi kebencanaan tersebut juga mendukung program pemerintah dalam pengurangan risiko bencana (ClarkGinsberg, 2020; Marfai et al., 2019). Secara khusus, Penguatan Literasi Mitigasi Bencana Angin Puting Beliung untuk Peningkatan Kapasitas Masyarakat Desa Munggur, Kabupaten Boyolali, Jawa Tengah diharapkan dapat meningkatkan literasi masyarakat tentang bencana angin puting beliung, meningkatkan kapasitas masyarakat dalam menghadapi bencana angin puting beliung dan mengurangi risiko bencana angin puting beliung.

\section{METODE}

Lokasi pelaksanaan kegiatan edukasi adalah Desa Munggur, Kecamatan Andong, Kabupaten Boyolali, Provinsi Jawa Tengah yang terletak terletak di antara S-7,343150 E110,739757 dan S-7,364137 E110,754510 (Gambar 3). Penggunaan lahan di Desa Munggur di antaranya permukiman 64,88 hektar, sawah irigasi 70,00 hektar, sawah tadah hujan 37,81 hektar, lahan kosong 1,45 hektar, tegalan dan kebun 12,65 hektar (BPS, 2019). Mata pencaharian yang paling banyak digeluti oleh masyarakat Desa Munggur adalah sebagai petani.

Materi bencana angin puting beliung serta upaya mitigasinya dipilih berdasarkan hasil overview dan diskusi dengan Kepala Desa dan beberapa tokoh masyarakat Desa Munggur. Selain itu, hasil diskusi juga diperkuat oleh riwayat kejadian bencana angin puting beliung di Kabupaten Boyolali berdasarkan studi literatur, BNPB serta laporan dari media elektronik. Tahap selanjutnya adalah penentuan metode edukasi yang tepat. Pemilihan metode dilakukan melalui diskusi dengan Kepala Desa. Berdasarkan hasil 
diskusi tersebut, maka disepakati menggunakan metode focus group discussion (FGD.

FGD disepakati dan dipilih karena dalam forum tersebut relatif efektif untuk transfer informasi dan pengetahuan, selain itu tujuan diskusi dapat lebih terarah dan tepat sasaran. Sarana dan prasarana yang digunakan meliputi aula/pendapa, kursi, meja, seperangkat soundsystem, proyektor, layar proyektor dan laptop. Aula/pendapa, kursi, meja, seperangkat soundsystem disiapkan oleh Kepala Desa Munggur, sedangkan proyektor, layar proyektor dan laptop disiapkan tim narasumber. Bahan yang digunakan dalam kegiatan edukasi disiapkan oleh tim narasumber. Bahan tersebut berupa slide presentasi tentang bencana angin puting beliung yang disusun berdasarkan sumber-sumber ilmiah baku. Bahan tersebut disiapkan dan digandakan sejumlah peserta yang hadir.
Peserta FGD adalah Kepala Desa Munggur, sebagian perangkat desa, perwakilan karang taruna, perwakilan PKK, ketua Rukun Tetangga (RT) / Rukun Warga (RW) dan masyarakat Desa Munggur secara umum. Waktu pelaksanaan disepakati bersama agar peserta dapat hadir, sehingga pelaksanaan FGD berjalan optimal. Waktu pelaksanaan edukasi disepakati Pukul 09.00 WIB. Jam tersebut merupakan kesepakatan bersama, sehingga tidak memberatkan masyarakat.

FGD dimulai dengan pemaparan materi ilmiah untuk meningkatkan pemahaman masyarakat secara ilmiah (scientific knowledge), kemudian dilanjutkan dengan sesi diskusi (tanya jawab) (Murti \& Mathez-Stiefel, 2019). Dalam sesi tanya jawab, masyarakat diberikan rangsangan (stimulus) untuk memberikan umpan balik tentang pengetahuan angin puting beliung berdasarkan pengetahuan local

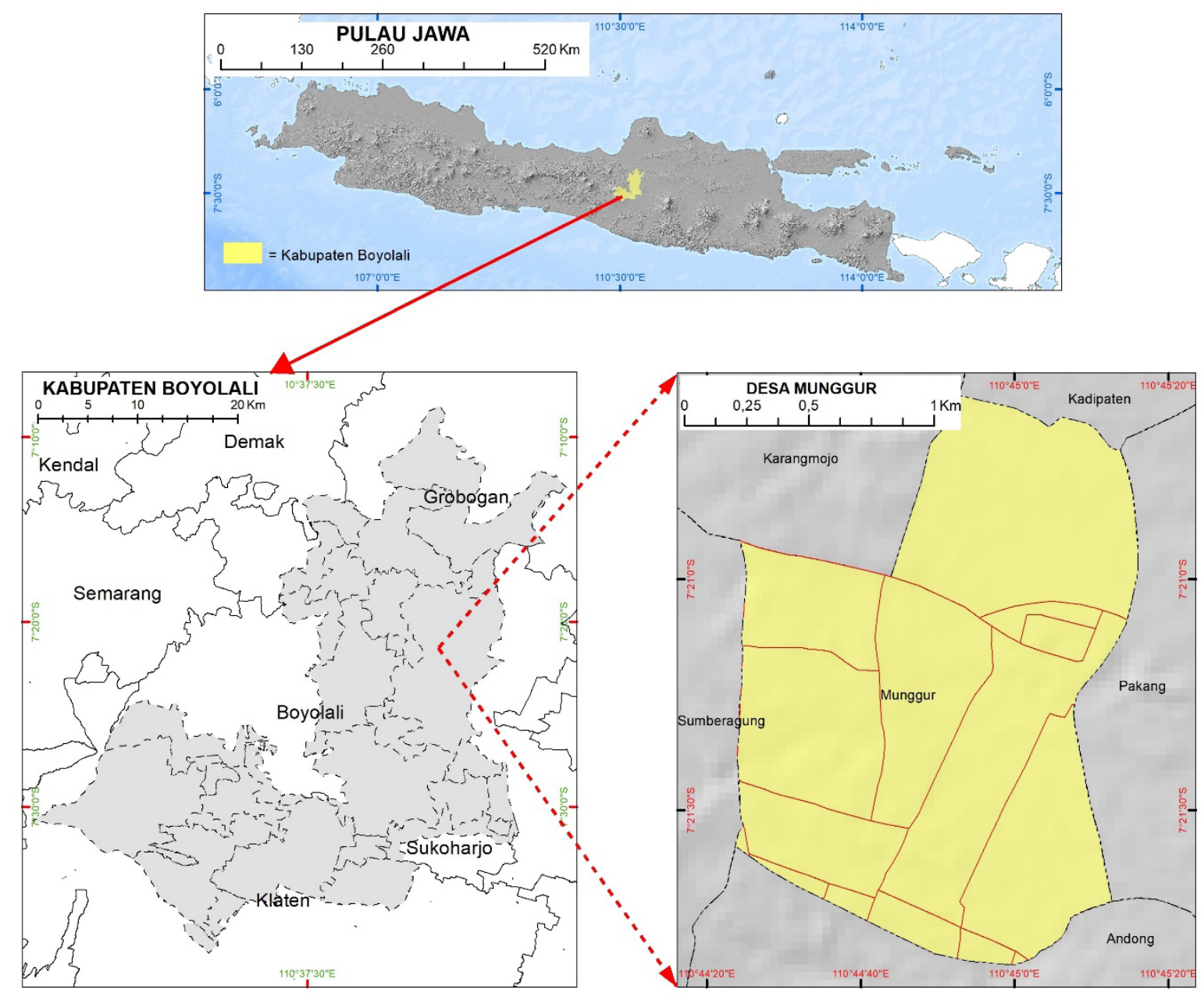

Gambar 3.lokasi pelaksanaan kegiatan edukasi untuk penguatan literasi mitigasi bencana angin puting beliung (Sumber: BIG, 2017) 
(local knowledge) atau kearifan lokal (local wisdom) yang secara turun temurun telah diketahui dan dilaksanakan. Dari hasil diskusi tersebut kemudian diperoleh kesesuaian antara pengetahuan ilmiah (scientific knowledge) dan kearifan lokal (local wisdom) masyarakat, sehingga diperoleh sinergi antara kedua jenis pengetahuan tersebut (Gambar 4). Kesesuaian tersebut bukan menghilangkan salah satu tetapi untuk saling melengkapi dan meluruskan pengetahuan atau informasi yang belum sempurna sebelumnya. Dalam proses diskusi mahasiswa berperan aktif sebagai penghubung sekaligus turut serta memberikan penjelasan kepada masyarakat tentang bencana angin puting beliung.

\section{HASIL DAN PEMBAHASAN}

\section{Identifikasi materi dan metode pelaksanaan} kegiatan

Dampak kejadian puting beliung di Desa Munggur adalah rusaknya harta benda milik masyarakat dan terganggunya aktivitas masyarakat, sehingga fenomena tersebut dapat diklasifikasikan sebagai bencana alam. Dampak negatif tersebut di antaranya menyebabkan korban luka, korban jiwa dan kerugian material sertadampakkultural (sosial-ekonomi) (Etinayet al., 2018). Oleh karena itu diperlukan manajemen bencana yang terstruktur. Manajemen bencana yang terstruktur dengan baik bukan hanya menjadi tanggung jawab pemerintah saja,

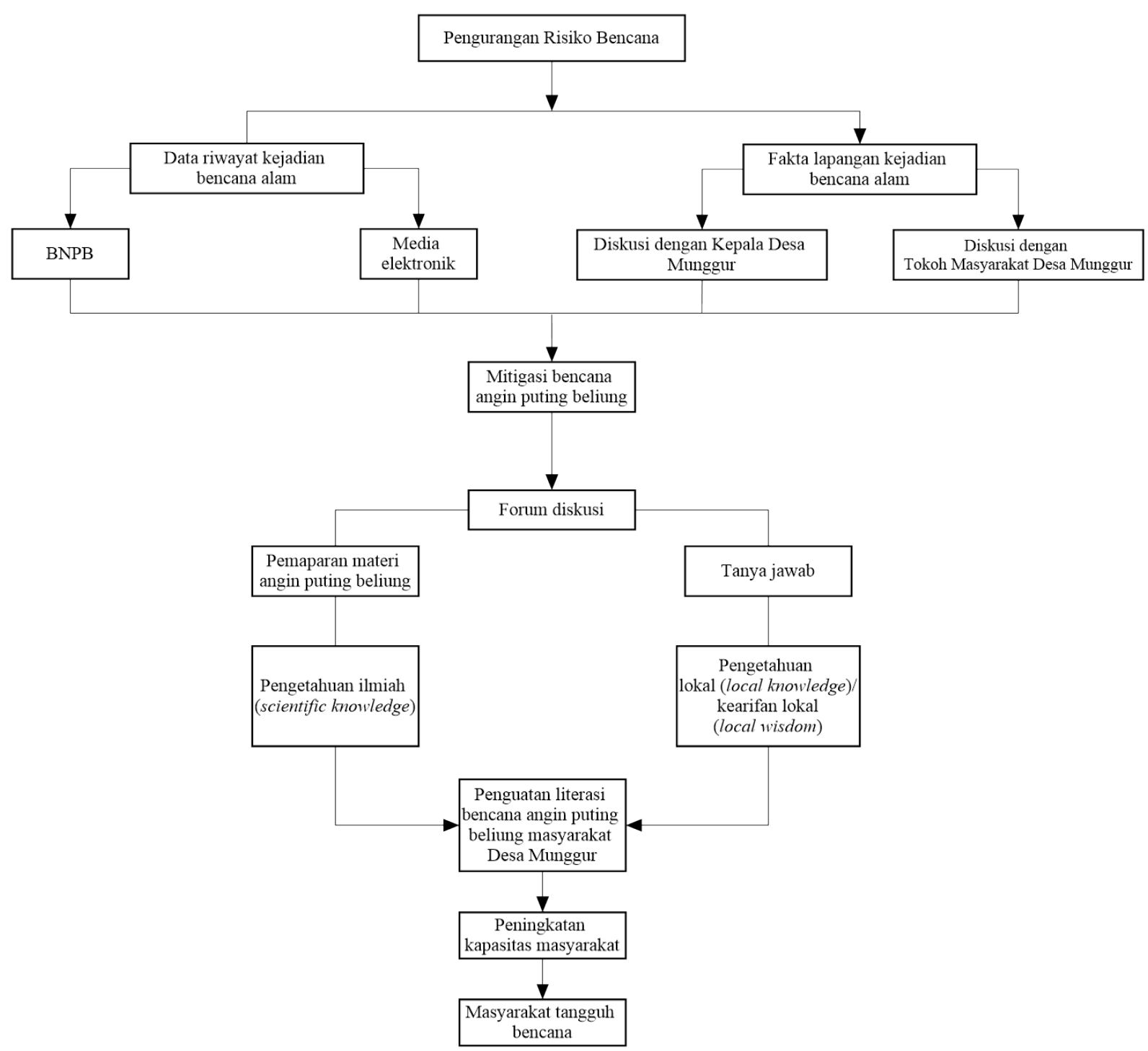

Gambar 4. Diagram Alir Pelaksanaan Edukasi untuk Penguatan Literasi Mitigasi Bencana Angin Puting Beliung untuk Peningkatan Kapasitas Masyarakat Desa Munggur, Kabupaten Boyolali, Jawa Tengah 
melainkan membutuhkan kesadaran dan kerja sama dengan masyarakat sebagai subyek utama dalam pengurangan risiko bencana (Fisher et al., 2019). Fakta tersebut diperoleh dari hasil overview dan wawancara singkat dengan kepala desa dan ketua Rukun Tetangga (RT) di Desa Munggur yang dilaksanakan 26 Januari 2020.

Dalam manajemen kebencanaan, fokus kegiatan dilaksanakan sebelum kejadian, pada saat kejadian dan pasca kejadian. Salah satu variabel penting dalam manajemen bencana adalah peningkatan kapasitas masyarakat yang tinggal di kawasan rawan bencana (Lee \& Chen, 2019; Mutasa \& Munsaka, 2019). Namun demikian, berdasarkan penuturan Kepala Desa Munggur, upaya peningkatan pengetahuan tentang mitigasi bencana puting beliung di Desa Munggur belum pernah dilakukan, baik oleh pemerintah melalui instansi terkait maupun organisasi sosial kemasyarakatan.

Penentuan materi bencana dan metode penguatan literasi dilakukan melalui diskusi dengan Kepala Desa dan tokoh masyarakat Desa Munggur yang diwakili oleh ketua RT. Hal itu dilakukan agar kegiatan yang akan dilakukan benar-benar sesuai dengan kondisi dan kebutuhan masyarakat. Hasil diskusi tersebut dapat disimpulkan bahwa kebutuhan masyarakat akan pengetahuan mitigasi bencana yang paling mendesak adalah mitigasi bencana puting beliung. Bencana angin puting beliung hampir setiap tahun melanda Desa Munggur dan menimbulkan kerugian, yaitu kerusakan lahan pertanian serta bangunan.

Pemerintah Desa Munggur sebenarnya sudah memiliki gagasan untuk melaksanakan program peningkatan pengetahuan tentang bencana angin puting beliung untuk masyarakat. Akan tetapi, belum adanya mitra atau narasumber untuk melaksanakan kegiatan menjadi kendala bagi pemerintah desa. Hal tersebut gayung bersambut dengan salah satu tri dharma perguruan tinggi, yaitu pengabdian kepada masyarakat. Akhirnya, diskusi dengan Kepala Desa dan beberapa tokoh masyarakat Desa Munggur menghasilkan kesepakatan, bahwa sebagai langkah awal dalam peningkatan kapasitas masyarakat Desa Munggur terhadap bencana angin puting beliung adalah edukasi melalui FGD.
Materi dalam diskusi meliputi pengetahuan dasar kebencanaan, proses terjadinya angin, proses terjadinya angin puting beliung, dampak angin puting beliung serta mitigasi bencana angin puting beliung, kemudian dilanjutkan tanya jawab tentang pemahaman masyarakat Desa Munggur tentang angin puting beliung berdasarkan pengetahuan lokal (local knowledge) serta kearifan lokal (local wisdom). Pelaksanaan kegiatan edukasi di Desa Munggur merupakan Langkah awal dalam pengurangan risiko bencana, sehingga hanya sampai tahap penyampaian materi secara teoritis yang dipadukan dengan pengalaman empiris masyarakat. Kegiatan tersebut belum mencapai tahap simulasi atau pelatihan penanggulangan bencana.

\section{Pelaksanaan Edukasi sebagai Penguatan Literasi Mitigasi Bencana Angin Puting Beliung untuk Peningkatan Kapasitas Masyarakat}

Edukasi melalui FGD sebagai Penguatan Literasi Mitigasi Bencana Angin Puting Beliung Untuk Peningkatan Kapasitas Masyarakat Desa Munggur dilaksanakan pada Hari Sabtu, 15 Februari 2020 di Balai Pertemuan Program Kesejahteraan Keluarga (PKK) Desa Munggur pukul 09.00 - 12.00 WIB. Kegiatan tersebut dihadiri oleh Kepala Desa, tokoh masyarakat dan 50 orang masyarakat Desa Munggur dari berbagai latar belakang tingkat pendidikan, pekerjaan maupun kondisi sosial ekonomi. Latar belakang masyarakat peserta diskusi yang beranekaragam tersebut merupakan salah satu hal positif karena proses transfer informasi dan pengetahuan menjadi lebih optimal.

FGD dimulai dengan pemaparan materi tentang angin puting beliung, dimulai dari proses terbentuknya hingga bentuk-bentuk mitigasinya. Pemaparan materi berlangsung selama 60 menit dan dilanjutkan tanya jawab selama 45 menit. Selama sesi pemaparan materi, peserta diskusi menyimak materi yang disampaikan, materi tersebut merupakan materi yang disusun berdasarkan teori-teori ilmiah dari sumber-sumber primer baku. Oleh karena itu, penyampaian materi dibuat lebih sederhana agar dapat diterima dan dipahami masyarakat dengan baik. Pemberian materi ilmiah sangat penting dilakukan untuk meningkatkan literasi 

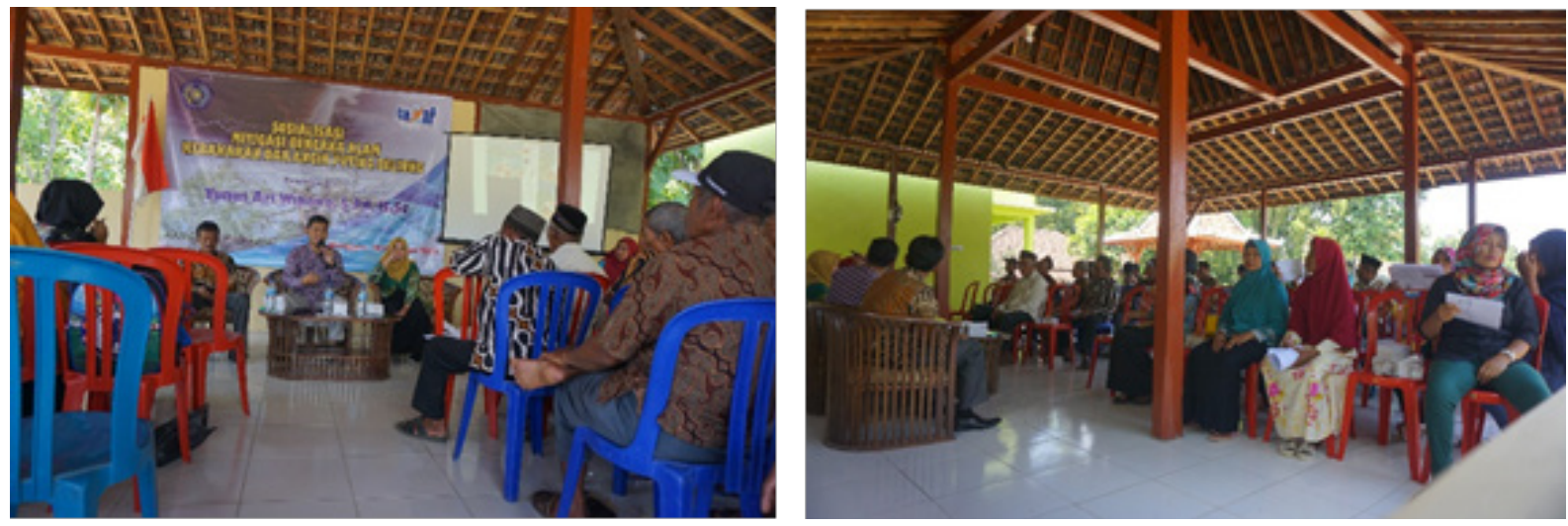

Gambar 5 Proses pemaparan materi berlangsung sangat kondusif dan berjalan dengan sangat menarik (Sumber: Dokumentasi lapangan, Februari 2020)

masyarakat tentang angin puting beliung secara ilmiah. Proses pemaparan materi berlangsung sangat kondusif dan berjalan dengan sangat menarik karena peserta sangat antusias untuk menyimak (Gambar 5).

Tahap selanjutnya adalah tanya jawab, dalam tahap ini ada beberapa pertanyaan mendasar masyarakat tentang materi yang disampaikan. Pertanyaan tersebut sesuai dengan yang diharapkan, yaitu mengarah pada istilah-istilah ilmiah yang baru diperoleh dalam sesi pemaparan materi. Melalui pertanyaanpertanyaan tersebut masyarakat diminta menyebutkan istilah-istilah lokal dari istilahistilah ilmiah yang sebelumnya ditanyakan. Sebagai contoh, istilah angin puting beliung meskipun sudah secara luas digunakan di Indonesia, namun masyarakat di Desa Munggur lebih terbiasa menyebutnya dengan istilah angin lesus, angin puyuh atau cleret tahun. Lebih lanjut, hampir semua masyarakat sudah mampu mengidentifikasi waktu kejadian, sebagaimana dicontohkan oleh para leluhurnya atau yang biasa disebut ilmu titen (kejelian orang jawa dalam menganalisa kejadian yang berulang). Berdasarkan pengetahuan lokal masyarakat Desa Munggur yang diwariskan secara turun menurun, angin puting beliung akan terjadi ketika pergantian musim (pancaroba).

Hal itu sesuai dengan teori-teori ilmiah yang disampaikan pada sesi sebelumnya. Lebih lanjut materi yang sangat penting bagi masyarakat Desa Munggur adalah detil tentang tandatanda mulai tumbuhnya angin puting beliung. Masyarakat Desa Munggur belum mengetahui ciri-ciri tumbuhnya angin puting beliung belum secara detil. Materi yang diberikan adalah ciri-ciri tumbuhnya angin puting beliung yang ditandai oleh udara panas atau terasa gerah, adanya pertumbuhan awan Cumulus (Cu) (awan putih yang bergerombol yang berlapis-lapis), terbentuknya kolom menyerupai bunga kol dan awan Cumulus tiba-tiba berubah warna dari warna putih menjadi warna hitam pekat (awan Cb). Tahap-tahap tumbuhnya angin puting beliung secara detil tersebut yang harus diketahui oleh masyarakat agar dapat segera menyelamatkan diri.

Selain materi ciri-ciri terbentuknya angin puting beliung, beberapa hal lain yang wajib disampaikan kepada masyarakat Desa Munggur adalah angin puting beliung tidak mempunyai periode ulang yang pasti, tidak ada angin puting beliung susulan, bersifat lokal dengan area terdampak radius 5-10 $\mathrm{km}^{2}$, hanya terjadi pada siang hingga sore hari, durasi kejadian sangat singkat 5-15 menit. Pengetahuan-pengetahuan tersebut dilengkapi dengan pengetahuan tanggap darurat pada saat angin puting beliung terjadi.

Pengetahuan tanggap darurat bencana angin puting beliung meliputi membawa masuk barang-barang berharga ke dalam rumah, menutup jendela dan pintu, mematikan semua aliran listrik dan peralatan elektronik, jika disertai hujan dan terasa petir akan menyambar, segera membungkuk, duduk kemudian peluk lutut ke dada, hindari tiarap di atas tanah terbuka, jika berada di lahan terbuka tiarap di selokan atau cekungan, menghindari bangunan yang tinggi, tiang listrik, papan reklame, ancaman puting beliung biasanya berlangsung 
5-15 menit, sehingga jangan terburu-buru keluar dari tempat perlindungan yang aman jika angin kencang belum benar-benar reda. Pengetahuanpengetahuan tambahan secara ilmiah sangat diperlukan untuk meningkatkan kapasitas masyarakat.

Materi terakhir yang disampaikan adalah mitigasi bencana angin puting beliung. Mitigasi tersebut merupakan tanggung jawab bersama masyarakat dan pemerintah. Beberapa bentuk mitigasi yang direkomendasikan untuk Desa Munggur adalah mitigasi secara struktural dan non struktural (Tabel 1). Kedua bentuk mitigasi tersebut dapat terlaksana dengan adanya sinergi antara pemerintah dan masyarakat.

Edukasi dengan pemaparan materi untuk mitigasi bencana juga dilakukan oleh Pahleviannur (2019), namun tema dan sasarannya berbeda. Tema pada edukasi tersebut adalah bencana tanah longsor dengan sasaran siswa sekolah dasar (SD) di sebagian wilayah Selo, Kabupaten Boyolali. Sosialisasi mitigasi bencana yang cukup berbeda dilakukan oleh Permana et al., (2013). Kegiatan tersebut menjadi menarik karena dilakukan dengan sasaran siswa SD dan sekolah menengah di perbatasan wilayah Suku Baduy. Kegiatan yang dilakukan oleh Pahleviannur (2019) tidak disertai tahap evaluasi kuantitatif, sedangkan kegiatan yang dilakukan oleh Permana et al., (2013) dilakukan evaluasi secara kuantitatif. Sama halnya seperti yang dilakukan oleh Supriyono et al., (2018), yaitu sosialisasi potensi bencana dan dilengkapi dengan evaluasi secara kuantitatif berupa pembagian kuesioner.

Edukasi untuk penguatan literasi mitigasi bencana angin puting beliung di Desa Munggur memiliki kemiripan metode tetapi dengan penciri yang berbeda dengan beberapa kegiatan tersebut. Kesamaan terletak pada penggunaan metode ceramah dan FGD (Pahleviannur, 2019; Permana et al., 2013; Supriyono et al., 2018), sasaran masyarakat secara umum (Supriyono et al., 2018) dan tidak melakukan evaluasi secara kuantitatif atau hanya melakukan penilaian secara kualitatif berdasarkan keaktifan masyarakat peserta edukasi (Pahleviannur, 2019). Lebih lanjut, penciri yang membedakan dengan kegiatan-kegiatan sebelumnya adalah integrasi antara pengetahuan ilmiah (scientific knowledge) dan pengetahuan lokal (local knowledge) yang diperoleh secara turun

Tabel 1. Bentuk-bentuk mitigasi bencana angin puting beliung yang direkomendasikan di Desa Munggur

\begin{tabular}{|c|c|c|}
\hline No. & Bentuk mitigasi & Pelaksana \\
\hline 1. & $\begin{array}{l}\text { Membuat struktur bangunan yang memenuhi syarat teknis untuk } \\
\text { mampu bertahan terhadap gaya angin }\end{array}$ & Masyarakat \\
\hline 2. & $\begin{array}{l}\text { Penempatan lokasi pembangunan fasilitas yang penting pada } \\
\text { daerah yang terlindung dari serangan angin }\end{array}$ & Pemerintah \\
\hline 3. & $\begin{array}{l}\text { Pengamanan barang-barang di sekitar rumah agar terikat } \\
\text { dibangun secara kuat sehingga tidak diterbangkan angin }\end{array}$ & Masyarakat \\
\hline 4. & $\begin{array}{l}\text { Menyusun peta rawan bencana puting beliung berdasarkan data } \\
\text { historis }\end{array}$ & Pemerintah \\
\hline 5. & $\begin{array}{l}\text { Sosialisasi mengenai puting beliung agar masyarakat memahami } \\
\text { dan mengenal puting beliung, baik definisi, gejala awal, } \\
\text { karakteristik, bahaya, dan mitigasinya }\end{array}$ & Pemerintah \\
\hline 6. & Penghijauan di bagian atas arah angin untuk meredam gaya angin & Pemerintah dan masyarakat \\
\hline 7. & $\begin{array}{l}\text { Pembuatan bangunan umum yang cukup luas yang dapat } \\
\text { digunakan sebagai tempat penampungan sementara bagi orang } \\
\text { maupun barang saat terjadi angin puting beliung }\end{array}$ & Pemerintah \\
\hline 8. & Pembuatan jalur evakuasi & Pemerintah dan masyarakat \\
\hline 9. & $\begin{array}{l}\text { Kesiapsiagaan dalam menghadapi angin puting beliung khususnya } \\
\text { tentang bagaimana cara penyelamatan diri }\end{array}$ & Pemerintah dan masyarakat \\
\hline
\end{tabular}


menurun yang menjadi bentuk kearifan lokal (local wisdom) masyarakat.

Pemaparan teori ilmiah tentang angin puting beliung bukan untuk "menyalahkan" bahkan "menghilangkan" kearifan lokal (local wisdom) masyarakat Desa Munggur, tetapi untuk digunakan sebagai dasar dalam memperkuat pengetahuan lokal (local knowledge). Melalui FGD tersebut, masyarakat mendapatkan informasi tentang padanan istilah tentang bencana angin puting beliung dalam teori ilmiah dan pengetahuan lokal. FGD tersebut sangat bermanfaat karena mensinergikan antara pengetahuan ilmiah (scientific knowledge) dan pengetahuan lokal (local knowledge). Terbentuknya sinergi tersebut akan membuat masyarakat Desa Munggur semakin mantab terhadap pengetahuan lokal (local knowledge) yang mereka miliki karena telah didukung teori-teori ilmiah. Dari sisi ilmu pengetahuan, informasi tentang istilah-istilah lokal tersebut mampu menambah khasanah keilmuan sesuai bidang kajian dan dapat dijadikan salah satu dasar dalam integrasi pengetahuan ilmiah dan pengetahuan lokal/kearifan lokal dalam mitigasi bencana. Diharapkan metode tersebut dapat digunakan juga di wilayah lain khususnya yang termasuk dalam Kawasan rawan bencana.

\section{Capaian pelaksanaan Edukasi untuk Penguatan Literasi Mitigasi Bencana Angin Puting Beliung Untuk Peningkatan Kapasitas Masyarakat}

Pelaksanaan edukasi sebagai Penguatan Literasi Mitigasi Bencana Angin Puting Beliung untuk Peningkatan Kapasitas Masyarakat Desa Munggur berjalan dengan sangat baik dan mendapatkan respon positif, baik dari masyarakat, pemerintah desa serta tokoh masyarakat Desa Munggur. Selain itu, kegiatan tersebut mampu memenuhi tujuan atau target awal kegiatan, yaitu menguatkan literasi masyarakat tentang bencana angin puting beliung. Literasi tentang bencana angin puting beliung meliputi proses terbentuknya angin puting beliung, waktu terbentuknya, dampak serta bentuk-bentuk mitigasinya (Tabel 2). Hal itu secara langsung berperan meningkatkan kapasitas masyarakat dalam menghadapi bencana angin puting beliung.
Tabel 2 menunjukkan klasifikasi informasi atau pengetahuan ilmiah yang disampaikan dan capaiannya dalam kegiatan edukasi. Dalam FGD terungkap fakta bahwa pengetahuan tentang bencana angin putting beliung yang dimiliki oleh masyarakat Desa Munggur masih sangat terbatas. Ada beberapa pengetahuan yang sudah diketahui secara turun temurun dan sesuai dengan kaidahkaidah ilmiah, namun ada juga yang sama sekali belum diketahui. Peningkatan pengetahuan ilmiah dan pemantapan pengetahuan lokal terintegrasi dalam kegiatan tersebut, sehingga potensi kerugian di masyarakat sebagai kelompok rentan dapat diminimalisasi.

Masyarakat merupakan salah satu kelompok rentan (element at risk) baik ditinjau dari sisi usia, jenis kelamin, tingkat pendidikan maupun kondisi ekonomi, sehingga diperlukan upaya peningkatan kapasitas untuk menurunkan tingkat kerentanannya. Menurunnya tingkat kerentanan masyarakat juga berperan mengurangi risiko bencana angin puting beliung di Desa Munggur. Keberhasilan pelaksanaan kegiatan dapat dilihat dari respon dan umpan balik dari warga setelah diskusi dilaksanakan. Hal itu mengindikasikan bahwa edukasi melalui FGD yang dilakukan memberikan kesan yang baik sesuai dengan konsep pembelajaran bermakna, sehingga akan diingat baik secara pelaksanaan maupun substansi teori untuk meningkatkan pengetahuan.

Pengetahuan masyarakat tentang bencana angin puting beliung meningkat dibuktikan dengan jawaban-jawaban yang diberikan masyarakat pada sesi konfirmasi hasil pemaparan materi. Meskipun baru dinilai secara kualitatif tetapi hal itu dapat dipertanggungjawabkan karena semua peserta FGD aktif dalam berinteraksi membahas materi yang disajikan dalam diskusi. Selanjutnya, masyarakat dan pemerintah Desa Munggur menghendaki pelaksanaan kegiatan lanjutan berupa simulasi tanggap darurat bencana angin puting beliung. Hal itu, sangat positif karena simulasi bencana merupakan tahap lanjutan setelah edukasi. Pengetahuan yang diperoleh dalam proses edukasi dapat dipraktekkan dalam simulasi dan diterapkan jika kondisi terburuk melanda. 
Tabel 2. Capaian transfer informasi tentang bencana angin puting beliung

\begin{tabular}{|c|c|c|c|c|}
\hline \multirow[t]{2}{*}{ No. } & \multirow[t]{2}{*}{ Pengetahuan ilmiah } & \multicolumn{2}{|c|}{$\begin{array}{c}\text { Pengetahuan } \\
\text { masyarakat }\end{array}$} & \multirow[t]{2}{*}{ Keterangan } \\
\hline & & Sebelum & Sesudah & \\
\hline 1. & definisi "bencana" & - & $\mathrm{V}$ & $\begin{array}{l}\text { Baru benar-benar memahami konsep bencana } \\
\text { pada saat FGD }\end{array}$ \\
\hline 2. & $\begin{array}{l}\text { Klasifikasi "bencana" } \\
\text { menurut BNPB }\end{array}$ & - & $\mathrm{V}$ & $\begin{array}{l}\text { Baru mengetahui pada saat FGD, sebelumnya } \\
\text { hanya mengetahui eruosi gunungapi, longsor, } \\
\text { banjir, gempabumi }\end{array}$ \\
\hline 3. & $\begin{array}{l}\text { Instansi yang membidangi } \\
\text { kebencanaan di Indonesia }\end{array}$ & - & $\mathrm{V}$ & $\begin{array}{l}\text { Sebagian besar baru mengetahui pada saat FGD, } \\
\text { hanya } 5 \text { warga yang sudah mengetahui sebelum } \\
\text { FGD }\end{array}$ \\
\hline 4. & Istilah ilmiah puting beliung & - & $\mathrm{V}$ & $\begin{array}{l}\text { Baru benar-benar memahami pada saat FGD, } \\
\text { sebelumnya lebih sering menggunakan istilah } \\
\text { local claret tahun }\end{array}$ \\
\hline 5. & Waktu kejadian & - & $\mathrm{V}$ & Baru benar-benar memahami pada saat FGD \\
\hline 6. & $\begin{array}{l}\text { Deteksi tumbuhnya angin } \\
\text { puting beliung }\end{array}$ & $\mathrm{V}$ & $\mathrm{V}$ & $\begin{array}{l}\text { Baru benar-benar memahami pada saat FGD, } \\
\text { sebelumnya baru mengetahui Ketika kolom angin } \\
\text { puting beliung sudah terbentuk, sehingga waktu } \\
\text { untuk evakuasi cenderung sangat singkat }\end{array}$ \\
\hline 7. & $\begin{array}{l}\text { Proses pertumbuhan angin } \\
\text { puting beliung }\end{array}$ & - & $\mathrm{V}$ & Baru benar-benar memahami pada saat FGD \\
\hline 8. & $\begin{array}{l}\text { Daur hidup angin puting } \\
\text { beliung }\end{array}$ & - & $\mathrm{V}$ & $\begin{array}{l}\text { Belum mengetahui dan baru benar-benar } \\
\text { memahami pada saat FGD }\end{array}$ \\
\hline 9. & $\begin{array}{l}\text { Estimasi luas area } \\
\text { terdampak }\end{array}$ & - & $\mathrm{V}$ & $\begin{array}{l}\text { Belum mengetahui dan baru benar-benar } \\
\text { memahami pada saat FGD }\end{array}$ \\
\hline 10. & Periode ulang & - & $\mathrm{V}$ & $\begin{array}{l}\text { Belum mengetahui dan baru benar-benar } \\
\text { memahami pada saat FGD }\end{array}$ \\
\hline 11. & $\begin{array}{l}\text { Penanganan saat angin } \\
\text { puting beliung terjadi }\end{array}$ & $\mathrm{V}$ & $\mathrm{V}$ & $\begin{array}{l}\text { Mengetahui melalui informasi secara turun } \\
\text { termurun dan baru benar-benar memahami pada } \\
\text { saat FGD }\end{array}$ \\
\hline 12. & $\begin{array}{l}\text { Penanganan setelah angin } \\
\text { puting beliung terjadi }\end{array}$ & $\mathrm{V}$ & $\mathrm{V}$ & $\begin{array}{l}\text { Mengetahui melalui informasi secara turun } \\
\text { termurun dan baru benar-benar memahami pada } \\
\text { saat FGD }\end{array}$ \\
\hline 13. & $\begin{array}{l}\text { Mitigasi bencana angin } \\
\text { puting beliung }\end{array}$ & - & $\mathrm{V}$ & Baru benar-benar memahami pada saat FGD \\
\hline
\end{tabular}

Sumber: FGD Bulan Februari 2020
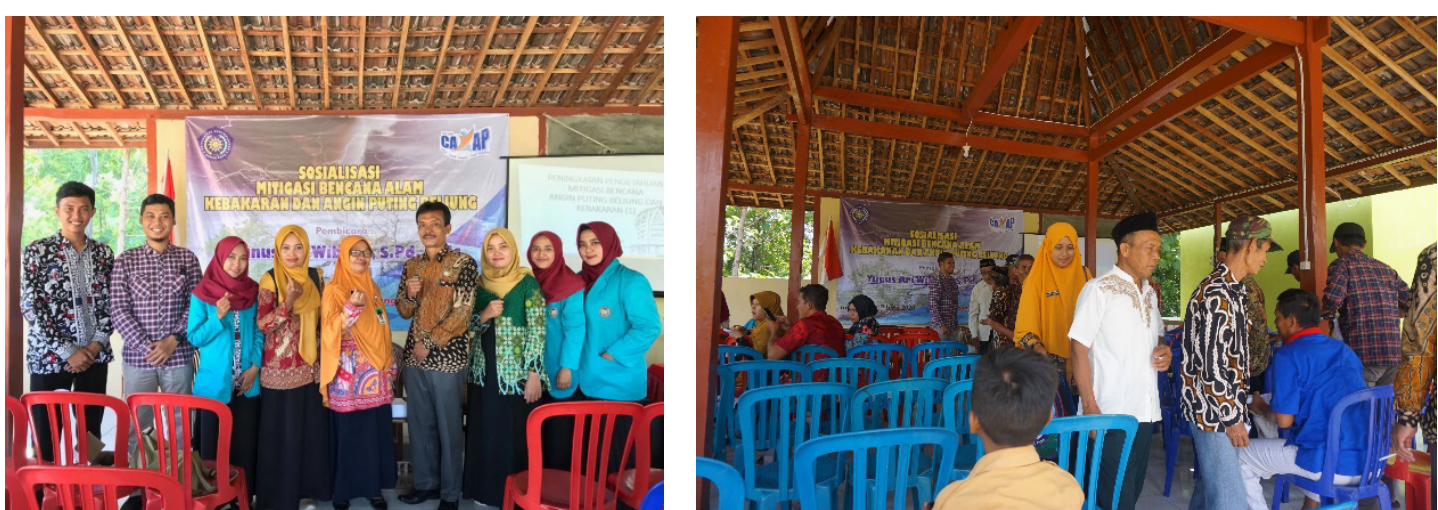

Gambar 6 Kerjasama unsur pemerintah desa, masyarakat dan akademisi pelaksanaan edukasi di Desa Munggur (Sumber: Dokumentasi lapangan, Februari 2020) 
Pelaksanaan edukasi tersebut merupakan kerjasama unsur pemerintah desa, masyarakat dan akademisi (Gambar 6). Peran aktif pemerintah desa, masyarakat dan akademisi dapat menjadi kunci keberhasilan mitigasi bencana. Peran aktif akademisi untuk terjun langsung ke masyarakat merupakan salah satu upaya paling efektif dalam penguatan literasi kebencanaan (Izumi et al., 2019; Spialek et al., 2016), baik pendidik seperti dosen maupun peserta didiknya, yaitu mahasiswa. Pendidik dapat melakukan transfer ilmu pengetahuan kepada peserta didik, sedangkan peserta didik dapat melanjutkan informasi yang diperoleh di dunia pendidikan kepada keluarga atau orang-orang di sekitarnya (Kamil et al., 2020). Lebih lanjut, baik pendidik maupun peserta didik juga dapat terjun langsung ke masyarakat untuk berperan aktif dalam peningkatan literasi masyarakat sesuai dengan bidang keahliannya masing-masing dan metode serta tahap-tahap pelaksanaan yang sistematis dalam pengurangan risiko bencana.

Selain bermanfaat bagi masyarakat Desa Munggur dalam penguatan literasi bencana angin puting beliung, kegiatan ini juga bermanfaat bagi mahasiswa yang turut terlibat dalam pelaksanaan kegiatan. Mahasiswa berperan aktif dalam penyampaian materi, hal itu sangat bermanfaat untuk melatih mental dalam berkomunikasi langsung kepada masyarakat. Kemampuan tersebut tidak dapat diperoleh di dalam kelas selama proses belajar mengajar tetapi dapat diperoleh dengan terjun langsung di masyarakat. Hal itu sejalan dengan visi merdeka belajar yang sedang digalakkan oleh kementerian pendidikan Indonesia untuk menyongsong generasi emas Indonesia 2045.

\section{SIMPULAN}

Pelaksanaan edukasi melalui FGD untuk penguatan literasi mitigasi bencana angin puting beliung untuk peningkatan kapasitas masyarakat Desa Munggur secara kualitatif dapat dinilai telah berjalan dengan sangat baik, kegiatan tersebut diharapkan dapat meningkatkan literasi masyarakat tentang bencana angin puting beliung. Peningkatan literasi tentang bencana angin puting beliung dapat meningkatkan kapasitas masyarakat Desa Munggur. Peningkatan kapasitas akan menurunkan tingkat kerentanan masyarakat. Sehingga tingkat risiko bencana angin puting beliung di Desa Munggur dapat diturunkan. Hal itu tercapai dengan metode yang tepat yaitu diskusi yang mengintegrasikan teori ilmiah (scientific knowledge) dan pengetahuan lokal (local knowledge) serta kearifan lokal (local wisdom) yang melibatkan unsur akademisi, pemerintah dan masyarakat. Diharapkan kegiatan ini menjadi awal atau dasar pelaksanaan kegiatan lanjutan dalam bidang kebencanaan untuk mencapai masyarakat tangguh bencana.

\section{PERSANTUNAN}

Ucapan terima kasih disampaikan kepada masyarakat Desa Munggur, Kepala Desa Munggur, mahasiswa Pendidikan Geografi, Fakultas Keguruan dan Ilmu Pendidikan, Universitas Muhammadiyah Surakarta serta semua pihak yang telah mendukung dan membantu pelaksanaan kegiatan ini.

\section{DAFTAR PUSTAKA}

Amaratunga, D., Malalgoda, C., Haigh, R., Panda, A., \& Rahayu, H. (2018). Sound Practices of Disaster Risk Reduction at Local Level. Procedia Engineering, 212(2017), 1163-1170. https://doi. org/10.1016/j.proeng.2018.01.150

BIG. (2017). Tanahair Indonesia. http://tanahair.indonesia.go.id/portal-web/download/perwilayah

BNPB. (2012). Peraturan Kepala Badan Nasional Penanggulangan Bencana Nomor 02 Tahun 2012 tentang Pedoman Umum Pengkajian Risiko Bencana (p. 62). BNPB.

BNPB. (2017). Data Informasi Bencana Indonesia (DIBI). http://bnpb.cloud/dibi/tabel1a 
BPS. (2019). Kecamatan Andong Dalam Angka 2019. https://boyolalikab.bps.go.id/

Clark-Ginsberg, A. (2020). Disaster risk reduction is not 'everyone's business': Evidence from three countries. International Journal of Disaster Risk Reduction, 43(March 2019), 101375. https://doi. org/10.1016/j.ijdrr.2019.101375

Der Sarkissian, R., Zaninetti, J. M., \& Abdallah, C. (2019). The use of geospatial information as support for Disaster Risk Reduction; contextualization to Baalbek-Hermel Governorate/Lebanon. Applied Geography, 111(August), 102075. https://doi.org/10.1016/j.apgeog.2019.102075

Diaz, J., \& Joseph, M. B. (2019). Predicting property damage from tornadoes with zero-inflated neural networks. Weather and Climate Extremes, 25(June), 100216. https://doi.org/10.1016/j. wace.2019.100216

Dube, E. (2020). The build-back-better concept as a disaster risk reduction strategy for positive reconstruction and sustainable development in Zimbabwe: A literature study. International Journal of Disaster Risk Reduction, 43, 101401. https://doi.org/10.1016/j.ijdrr.2019.101401

Etinay, N., Egbu, C., \& Murray, V. (2018). Building Urban Resilience for Disaster Risk Management and Disaster Risk Reduction. Procedia Engineering, 212(2017), 575-582. https://doi.org/10.1016/j. proeng.2018.01.074

Fisher, B., Atwell, A., Iles, I., \& Herovic, E. (2019). TornadoWarning: Understanding the National Weather Service' s communication strategies. Public Relations Review, January, 101879. https:// doi.org/10.1016/j.pubrev.2019.101879

Gaillard, J. C., van Niekerk, D., Shoroma, L. B., Coetzee, C., \& Amirapu, T. (2019). Wildlife hazards and disaster risk reduction. International Journal of Disaster Risk Reduction, 33(August), 55-63. https://doi.org/10.1016/j.ijdrr.2018.09.009

Iizuka, A. (2020). Developing Capacity for Disaster Risk Reduction: Lessons Learned from a Case of Sri Lanka. Progress in Disaster Science, 100632. https://doi.org/https://doi.org/10.1016/j. pdisas.2020.100073

Izumi, T., Shaw, R., Djalante, R., Ishiwatari, M., \& Komino, T. (2019). Disaster risk reduction andinnovations. Progress in Disaster Science, 2, 100033. https://doi.org/10.1016/j.pdisas.2019.100033

jateng.inews.id. (2019). Angin Puting Beliung terjang Boyoyali 3 Rumah Rata dengan Tanah. https:// jateng.inews.id/berita/angin-puting-beliung-terjang-boyoyali-3-rumah-rata-dengan-tanah

Kamil, P. A., Utaya, S., Sumarmi, \& Utomo, D. H. (2020). Improving disaster knowledge within high school students through geographic literacy. International Journal of Disaster Risk Reduction, 43, 101411. https://doi.org/10.1016/j.ijdrr.2019.101411

Lee, H. C., \& Chen, H. (2019). Implementing the Sendai Framework for disaster risk reduction 20152030: Disaster governance strategies for persons with disabilities in Taiwan. International Journal of Disaster Risk Reduction, 41(August), 101284. https://doi.org/10.1016/j.ijdrr.2019.101284

Lim, J., Loveridge, S., Shupp, R., \& Skidmore, M. (2017). Double danger in the double wide: Dimensions of poverty, housing quality and tornado impacts. Regional Science and Urban Economics, 65, 1-15. https://doi.org/10.1016/j.regsciurbeco.2017.04.003

Marfai, M. A., Cahyadi, A., Fatchurohman, H., Rosaji, F. S. C., \& Wibowo, Y. A. (2019). Tsunami preparedness and environmental vulnerability analysis in Kukup Beach, Gunungkidul, Indonesia. IOP Conference Series: Earth and Environmental Science, 256(1). https://doi.org/10.1088/1755$1315 / 256 / 1 / 012025$

Marshall, T. (2020). Risk Perception and Safety Culture : Tools for Improving the Implementation of Disaster Risk Reduction Strategies Abstract. International Journal of Disaster Risk Reduction, 101557. https://doi.org/10.1016/j.ijdrr.2020.101557 
Wibowo, dkk - Penguatan Literasi Mitigasi Bencana Angin Puting Beliung ...

Murti, R., \& Mathez-Stiefel, S. lan. (2019). Social learning approaches for ecosystem-based disaster risk reduction. International Journal of Disaster Risk Reduction, 33, 433-440. https://doi. org/10.1016/j.ijdrr.2018.09.018

Mutasa, S., \& Munsaka, E. (2019). Botswana and international policies on the inclusion of disaster risk reduction in the school curriculum: Exploring the missing link. International Journal of Disaster Risk Reduction, 40(August), 101271. https://doi.org/10.1016/j.ijdrr.2019.101271

news. okezone.com. (2019). Puting Beliung Terjang Boyolali Rumah Warga Rusak Tertimpa Pohon. https://news.okezone.com/read/2019/12/26/512/2146140/puting-beliung-terjang-boyolalirumah-warga-rusak-tertimpa-pohon

news.okezone.com. (2019). Belasan Rumah Warga Boyolali Rusak Diterjang Puting Beliung. https:// news.okezone.com/read/2019/11/21/512/2132953/belasan-rumah-warga-boyolali-rusakditerjang-puting-beliung

Pahleviannur, M. R. (2019). Edukasi Sadar Bencana Melalui Sosialisasi Kebencanaan Sebagai Upaya Peningkatan Pengetahuan Siswa Terhadap Mitigasi Bencana. Jurnal Pendidikan Ilmu Sosial, 29(1), 49-55. https://doi.org/10.23917/jpis.v29i1.8203

Permana, R. C. E., Nasution, I. P., Nugroho, Y. A., \& Putra, H. (2013). Sosialisasi Kearifan Lokal Masyarakat Baduy Dalam Mitigasi Bencana di Perbatasan Wilayah Baduy. Paradigma: Jurnal Kajian Budaya, 4(1), 27-41. http://paradigma.ui.ac.id/index.php/paradigma/issue/view/14

Pertiwi, P., Llewellyn, G., \& Villeneuve, M. (2020). Disability representation in Indonesian disaster risk reduction regulatory frameworks. International Journal of Disaster Risk Reduction, 45, 101454. https://doi.org/10.1016/j.ijdrr.2019.101454

Proulx, K., \& Aboud, F. (2019). Disaster risk reduction in early childhood education: Effects on preschool quality and child outcomes. International Journal of Educational Development, 66(October 2017), 1-7. https://doi.org/10.1016/j.ijedudev.2019.01.007

Refan, M., Romanic, D., Parvu, D., \& Michel, G. (2020). Tornado loss model of Oklahoma and Kansas, United States, based on the historical tornado data and Monte Carlo simulation. International Journal of Disaster Risk Reduction, 43, 101369. https://doi.org/10.1016/j.ijdrr.2019.101369

Spialek, M. L., Czlapinski, H. M., \& Houston, J. B. (2016). Disaster communication ecology and community resilience perceptions following the 2013 central Illinois tornadoes. International Journal of Disaster Risk Reduction, 17, 154-160. https://doi.org/10.1016/j.ijdrr.2016.04.006

Stokoe, R. M. (2016). Putting people at the centre of tornado warnings: How perception analysis can cut fatalities. International Journal of Disaster Risk Reduction, 17, 137-153. https://doi. org/10.1016/j.ijdrr.2016.04.004

Strader, S. M., Ashley, W. S., Pingel, T. J., \& Krmenec, A. J. (2018). How land use alters the tornado disaster landscape. Applied Geography, 94(March 2017), 18-29. https://doi.org/10.1016/j. apgeog.2018.03.005

Supriyono, S., Guntar, D., Edwar, E., Zairin, Z., \& Sugandi, W. (2018). Sosialisasi Potensi Bencana dan Sistem Informasi Geografi (SIG) Kebencanaan di Kabupaten Seluma. Jurnal Bagimu Negeri, 2(1), 59-68. https://doi.org/10.26638/jbn.552.8651

Undang-undang Republik Indonesia Nomor 24 Tahun 2007 tentang Penanggulangan Bencana. (2007). https://doi.org/10.23943/9781400889877

UNISDR. (2009). UNISDR Terminology on Disaster Risk Reduction. United Nations.

Wamsler, C., \& Johannessen, A. (2020). Meeting at the crossroads? Developing national strategies for disaster risk reduction and resilience: Relevance, scope for, and challenges to, integration. International Journal of Disaster Risk Reduction, 45, 101452. https://doi.org/10.1016/j.ijdrr.2019.101452 
Wang, Z., Liu, J., Xu, N., Fan, C., Fan, Y., He, S., Jiao, L., \& Ma, N. (2019). The role of indigenous knowledge in integrating scientific and indigenous knowledge for community-based disaster risk reduction: A case of Haikou Village in Ningxia, China. International Journal of Disaster Risk Reduction, 41. https://doi.org/10.1016/j.ijdrr.2019.101309

Wibowo, Y. A., Ronggowulan, L., Arif, D. A., Afrizal, R., Anwar, Y., \& Fathonah, A. (2019). Perencanaan Mitigasi Bencana Banjir Non-Struktural Di Daerah Aliran Sungai Comal Hilir, Jawa Tengah. JPIG (Jurnal Pendidikan Dan Ilmu Geografi), 4(2), 87-100. https://doi.org/10.21067/jpig.v4i2.3632

www.solopos.com. (2009). Angin Puting Beliung Terjang Andong. https://www.solopos.com/anginputing-beliung-terjang-andong-9931 